\title{
Structural Analysis of a Segment in Qatar-Kazerun Fault Using Satellite Images of Landsat 8
}

\author{
Soraya Dana, Mahmood Almasian, Mahyar Soltani, Shima Rahmati Kamel \\ Faculty of Basic Sciences, Department of Geology, Islamic Azad University, North Tehran Branch, Tehran, Iran \\ Email: Sorayadana1@gmail.com
}

Received 31 May 2015; accepted 17 July 2015; published 20 July 2015

Copyright (C) 2015 by authors and Scientific Research Publishing Inc.

This work is licensed under the Creative Commons Attribution International License (CC BY).

http://creativecommons.org/licenses/by/4.0/

(c) (i) Open Access

\section{Abstract}

The north-south Qatar-Kazerun fault, with an estimated 450-km length, is a fault with lithic basement. It is mostly covered by young Quaternary alluvium, which has led to obscurities of rock structure and fractures. As residential areas (such as Nour-Abad, Khumeh Zar, Qaemiyeh and Kamaraj) are mainly placed on plains covered by Quaternary alluvium, telemetry methods, especially structural analyses based on satellite images, which are nowadays regarded as good complements to field studies. That is why many satellites are recently launched for different scientific objectives. Landsat is one of these research satellites; it is for long helping scientists in different fields of natural sciences. The present paper enjoys the latest information obtained through Landsat 8. Using several image reproducing operations and assistant software, it draws a new structure for the area and presents it for further analysis and interpretation.

\section{Keywords}

Qatar-Kazerun Fault, Landsat 8, Telemetry, Structural Analysis

\section{Introduction}

In general, remote sensing can be called acquiring information technology and land imaging using aeronautical equipment such as aircraft or space equipment such as satellites [1] [2]. Nowadays, remote sensing technology and satellite images are used in various fields such as fault detection, mine exploration, petrology and mapping [3] [4]. The required data is collected by a sensor. After an analysis, the collected data is integrated with other layers of information in GIS system. The integrated data is prepared for the user. In this stage, the integrated data is interpreted by using various methods. In addition to data interpretation, images are interpreted to identify 
various phenomena with regard to their importance.

\section{Materials and Methods}

A scene of the study area is required in order to use Landsat satellite images. Each scene is determined with a path and a row. The study zone was located in the north and north-western city of Shiraz (Figure 1). As a case, this research selected Iran's Zagros zone. This region due to the geological dynamics is considered by many geologists [5]. In this regard, the framework of Haji Abad was selected as a case study because of its convenient location for structural and fault analysis.
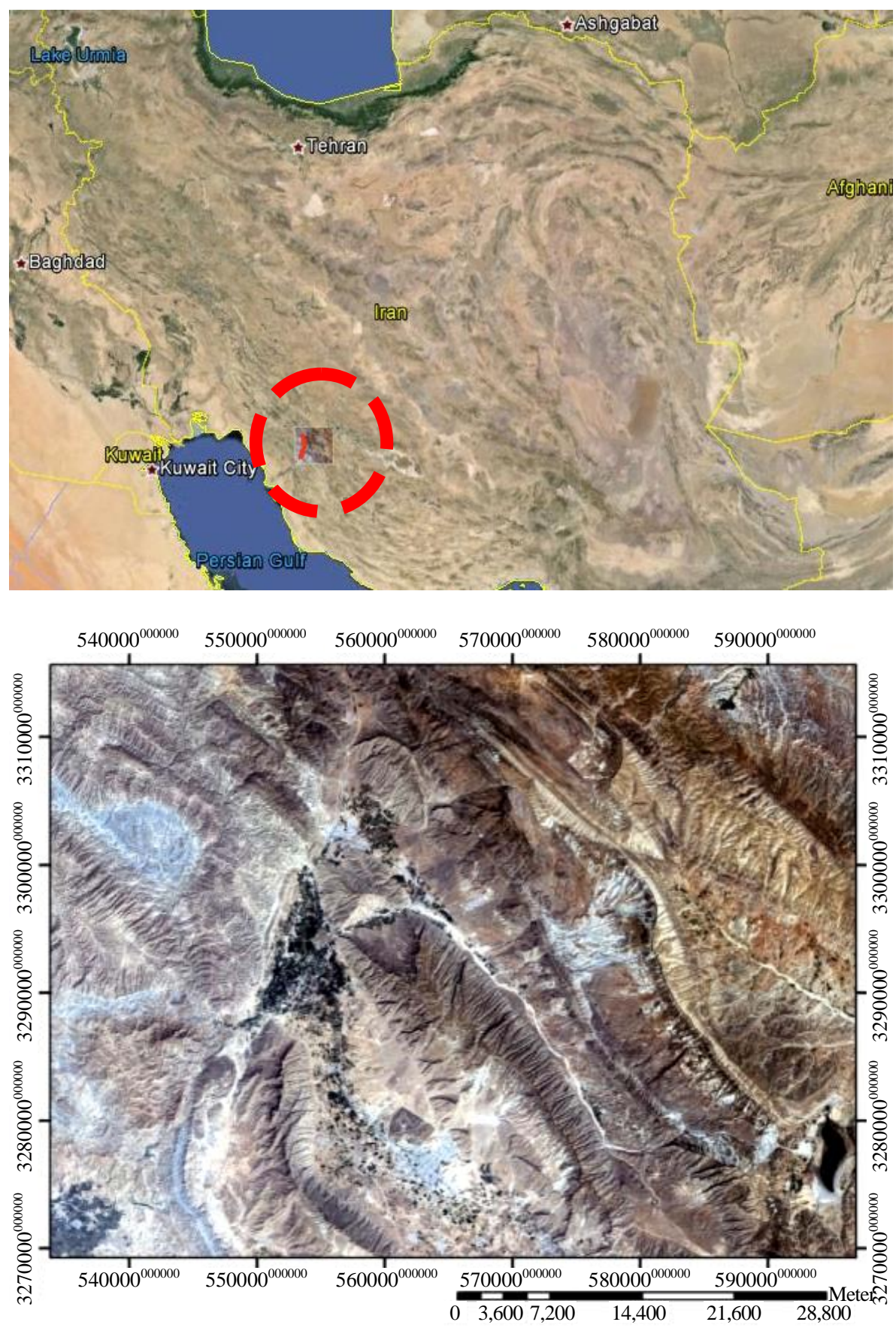

Figure 1. 1:250,000 geological map and satellite images of the study area. 
The first stage in image processing is called pre-processing, which should be done before processing operations. Given that remote sensing data is mainly used as a background for other information embedded in the map, remote sensing data significantly shows surface of the earth with sufficient accuracy [6]. In other words, spectral ratios of the image should be close to the truth.

Usually, raster images are stored as raw images with geometric errors. Geometrically corrected images are needed for accurate coordinates, area and measurements [7].

Geometric correction of satellite images resolve errors and distortions in the image such as changes in height and speed of the satellite, displacement in terms of height and lowness and other factors, which are cited in the following.

The purpose of processing images lies in clarifying geographical data in digital images in order to extract certain information for the user. A digital image is stored in a two-dimensional array by small limited areas, which are called pixels [8] [9].

Each pixel spatially coincides with an area on surface of the Earth. This orderly network structure is called raster. Digital data are generally in raster from, which are stored in horizontal and vertical rows. Each pixel in the raster image is a numerical value, which is called digital number (DN). In satellite images such as Landsat, DN represents intensity of the reflected energy in the visible spectrum, infrared or other electromagnetic rays. Mathematical transformations on digital numbers with ER Mapper software are used to extract and interpret digital data. This technique is impossible in manual interpretations. For this purpose, image processing has become an interpretation tool for various fields of Geoscience [9] [10].

One scene of digital data and ETM Landsat satellite were used for structural analysis. Images should be corrected using control points when precise coordinates, areas and measurements are needed. Here tectonic maps of Iran are used as a reference. Basic geometric corrections were made in compliance with image registration. Geological and tectonic maps of the area were digitized using ArcGIS software in order to adapt the maps with satellite images. The prepared images were processed. In this regard, ER-Mapper software was used due to different applications as well as easier and more accurate processing. This section briefly discusses the techniques used in this study.

\subsection{Satellite Image Processing}

Three methods were used to detect fracture lines in satellite images as follows:

a) Detection of displacement in layers and sudden changes in lithologic boundaries;

b) A review of direct valleys as fracture zones;

c) A review of fault bluff or dikes [9] [11].

In this section, remote sensing techniques were used for better visibility and drawing fracture lines using unique methods.

\subsection{The Techniques Used in This Study}

- The techniques used in this project are as follows:

- Using band ratios to eliminate the effects of topography and shadows;

- Color combination of RGB images to separate rock units based on color;

- Apply fusion in order to increase the spatial resolution;

- NDVI Vegetation to highlight begetation in the area;

- Apply Sunangle, Highpass and Edges filters to detect fractures lines, borders and sharp edges;

- Using DEM images for better visibility of valleys by the created shadows;

- Principal component analysis (PCA) in order to focus the data relevant to multiple bands in one band for better visibility from sharp edges;

- Band ratio to observe minerals and other complications associated with the fault. In this section, the techniques used in this project are discussed.

\section{Result and Discussion}

\subsection{Using Band Ratio}

This technique is used for distinguishing various phenomena by the differences in absorption and reflection of 
light in different phenomena (Figure 2). Eliminating the effect of topography and shadows can be cited among advantages of this method, which can be applied on two image types:

A. On grayscale images;

B. On RGB color images.

Grayscale images relevant to the above phenomenon are brighter due to maximum reflection and absorption properties compared to other image types. For example, vegetation and rocks in hydrothermal alteration appear brighter than other areas in grayscale images with 6/7 ratio.

\subsection{Color Combination of RGB Images}

Retina in human eyes is composed of a large number of rod and cone cells. The rod cells are sensitive to light and cone cells are sensitive to three primary colors of red, green and blue. In fact, the cone cells are commonly sensitive to a part of the electromagnetic rays. In color images, each phenomenon is assigned to one of the three primary colors. Each color represents a phenomenon in the image. The images were displayed in RGB space in order to separate phenomena (vegetation, rocks with hydrothermal alteration) from each other (Figure 3). In general, phenomena are clarified better and are interpreted easier using color images compared to black and white images. In fact, RGB false color images (red-green-blue) is one of the most common approaches in processing satellite data [12]. A color image is constructed by a combination of three different bands and assigning each one of the three primary colors to one band. The band combination of RGB $=432$ shows true color in nature, which is called true color composite. Any other combination except RGB = 432 is called false color composite [13].

Since three bands are needed to construct an RGB image, it should be considered how many unique combination modes are possible using 2, 3, 4, 5, 7, 8, 10 and 11 bands.

$$
X=n ! / r !(N-r) !
$$

$n$ is the number of total bands;

$r$ is the number of applied bands.

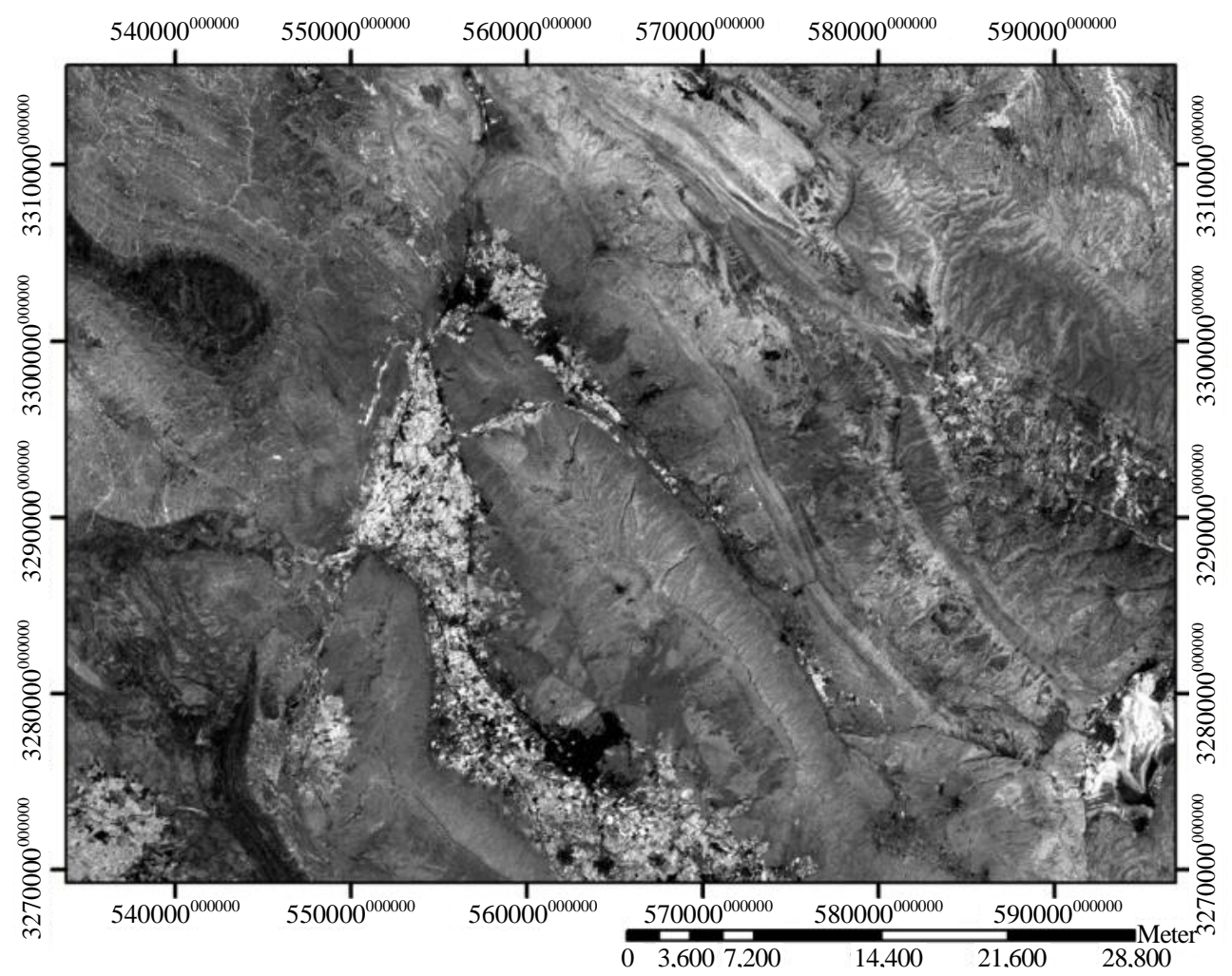

Figure 2. Vegetation appears brighter than other objects in grayscale at 5/4 ratio. 


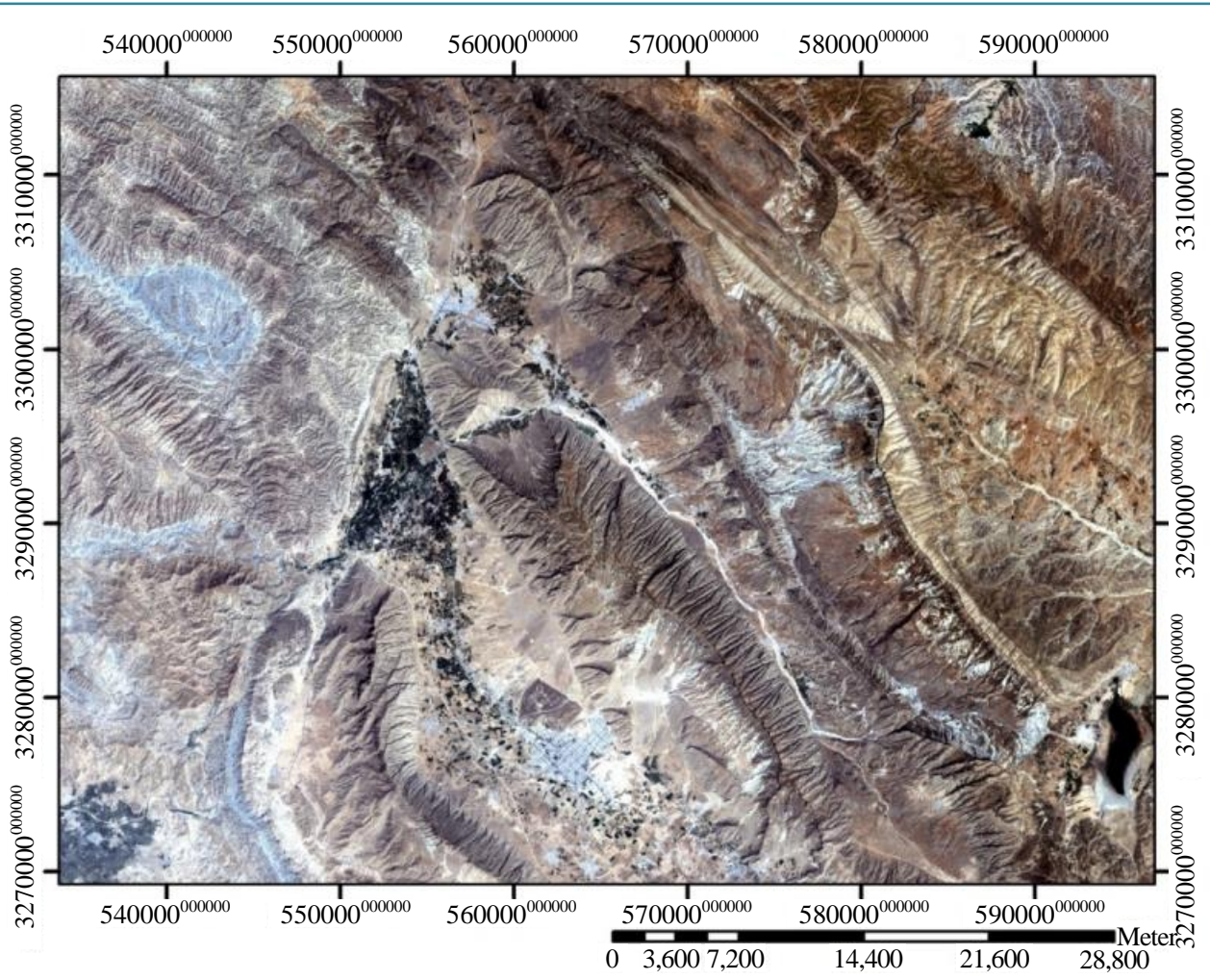

Figure 3. LANDSAT satellite image, RGB $=432$.

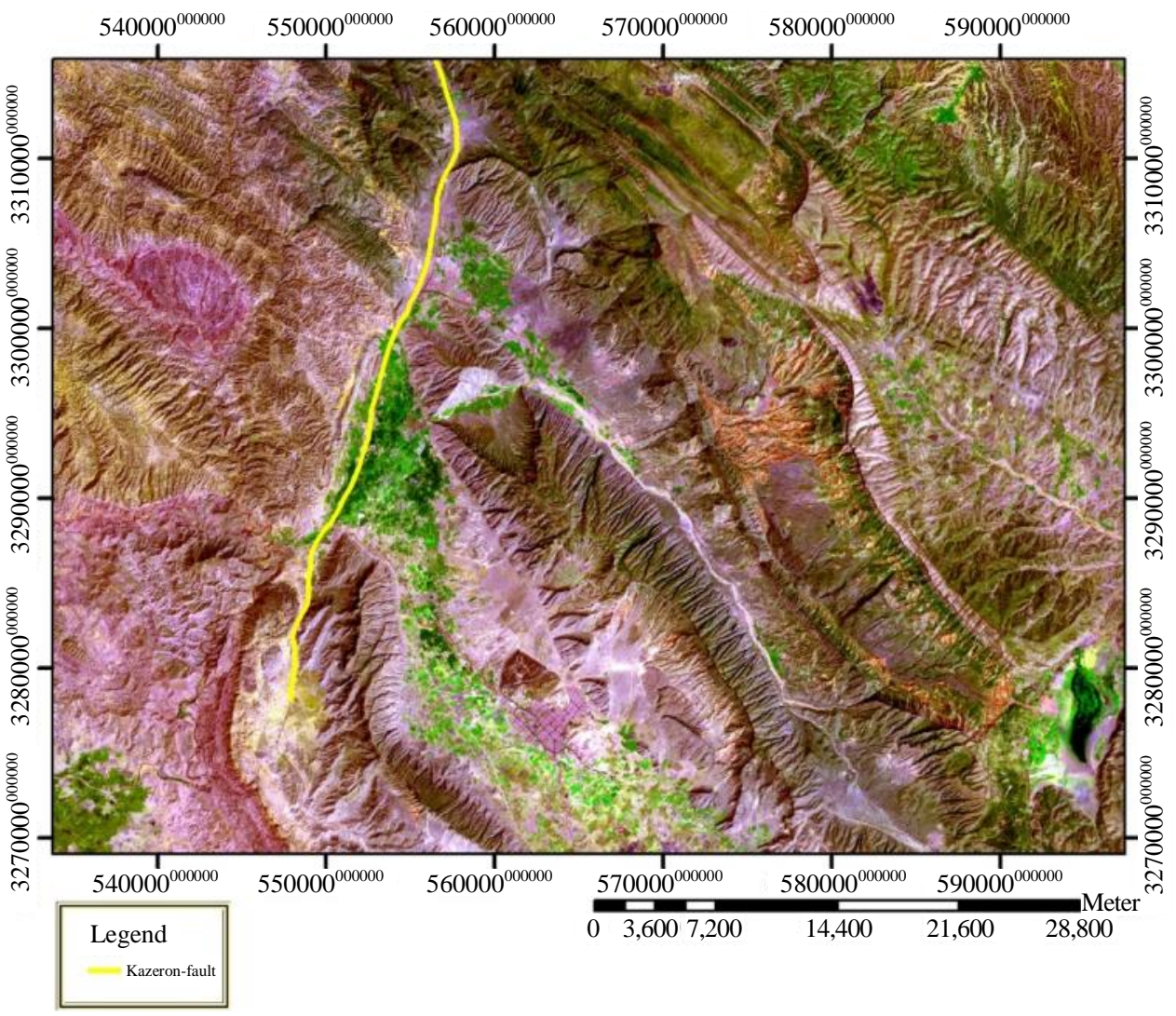

Figure 4. LANDSAT satellite image, the optimum combination of color RGB $=457$. 
Then, 56 combination modes are possible by inserting the numbers in the formula. However, more information is needed to select the best combination among possible ones. Thereby, statistical parameters should be used.

Optimum Index Factor (OIF) should be used to calculate statistical parameters of the images [10] [14]. In this parameter, sum of standard deviations of $\mathrm{k}$ bands are calculated with respect to sum of correlation matrix. Accordingly, three bands with the greatest information and the least share are determined. At the end, combination band $=457$ was selected as the optimum combination (Figure 4).

$$
\begin{aligned}
& \text { OIF }=\frac{\sum_{k=1}^{3} S_{k}}{\sum_{j=1}^{3} A b s} \\
& S_{k}=\text { Standard Deviation; } \\
& A b s(r j)=\text { correlation matrix value. }
\end{aligned}
$$

\subsection{Applying Fusion}

Fusion integration of ordinary images with panchromatic images or any other image improves spatial resolution. At this stage, RGB images were converted into HSI. The band with high special resolution was replaced with intensity. As shown in Figure 5, the image is retransferred from HSI space to RGB space. Then, panchromatic band or the eight bands was applied to the Landsat satellite images in order to reduce spatial resolution from 30 $\mathrm{m}$ to $15 \mathrm{~m}$. This improved spatial resolution of satellite images. RGB $=345$ was one of the best virtual color combinations used to more clearly identify the faults and geological units.

\subsection{Normalized Difference Vegetation Index (NDVI)}

Normalized difference vegetation index (NDVI) is one of the oldest and most widely used vegetation indexes.

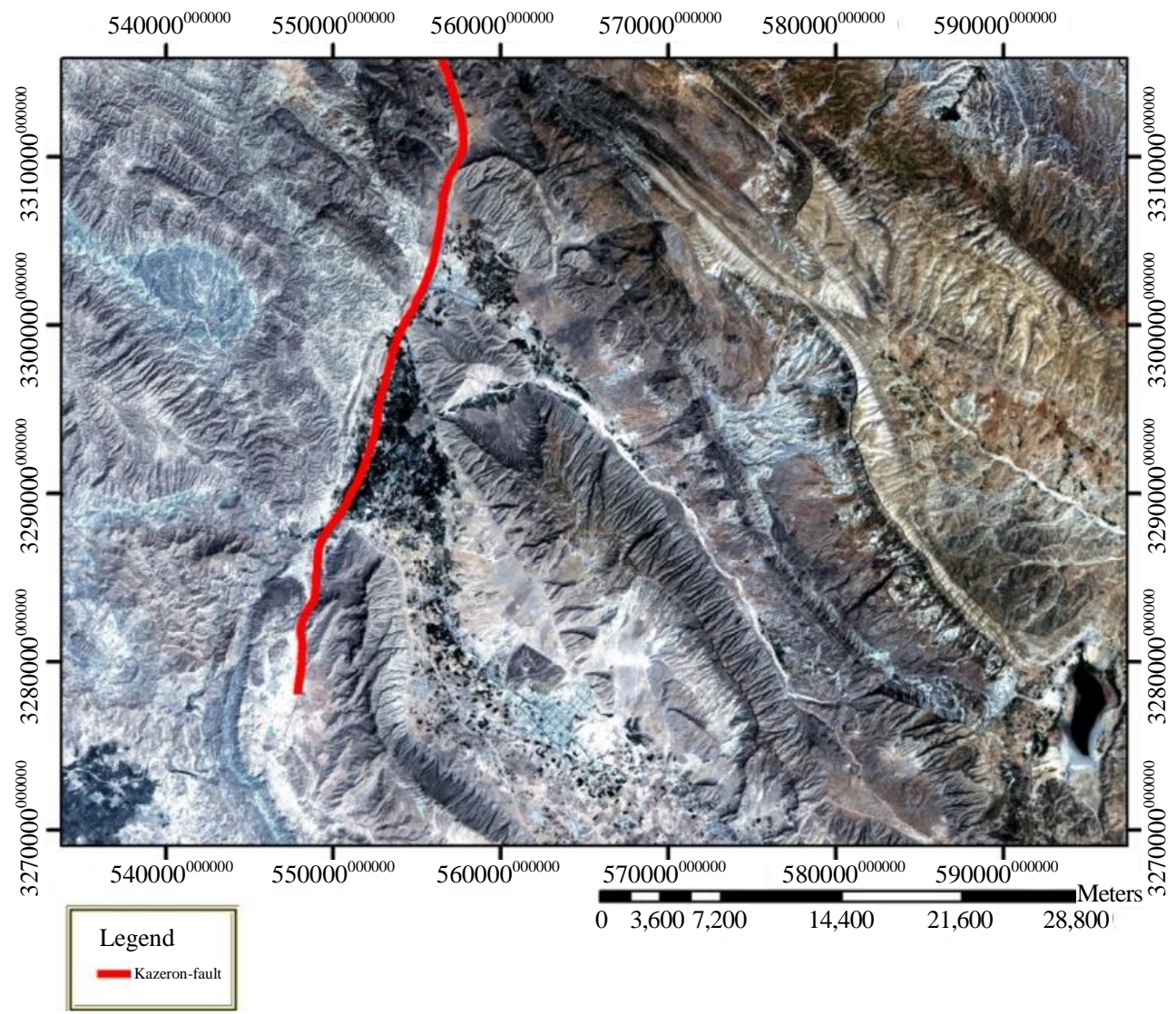

Figure 5. Fused image of the study area. 
According to Figure 6, normalized equation of the index and on the other hand, a wide range of the electromagnetic spectrum including maximum absorption and reflection of chlorophyll revealed that this index is stable and reliable in a wide range of different conditions. It should be noted that this index is saturated in case of high LAI values. The value of this index varies for different vegetation [15].

For example, total values of this index for sparse vegetation are $(0.05,0,2)$, for regular and semi-dense vegetation are $(0.2,0.6)$, for very dense and rich vegetation are $(0.6,0.8)$, for water, snow and ice are negative. Values of this index are less than 0.05 in soil. Value of this index in overcast (cloudy) areas is equal to zero. This method is used to identify faults in the region.

$$
\mathrm{NDVI}=\frac{\rho N I R-\rho R E D}{\rho N I R+\rho R E D}
$$

\subsection{Principal Component Analysis}

PCA is an important method in phenomena clarification. Usually, different bands of satellite images are highly correlated, which leads to repetition of some pieces of information. PCA is a reducing method for the repeated information and intruding phenomena such as shadows, topographic effects, and solar radiation angle. Indeed, by reducing the overlapping between data from different bands on a multi-dimensional space, PCA helps to clarify particular phenomena. In this method, information from strongly correlated bands is focused in a band with high variance. Principal components are obtained through calculation of standard deviation, variance, and covariance. PCA is a linear transformation through which coordinate axes of multi-dimensional space are turned

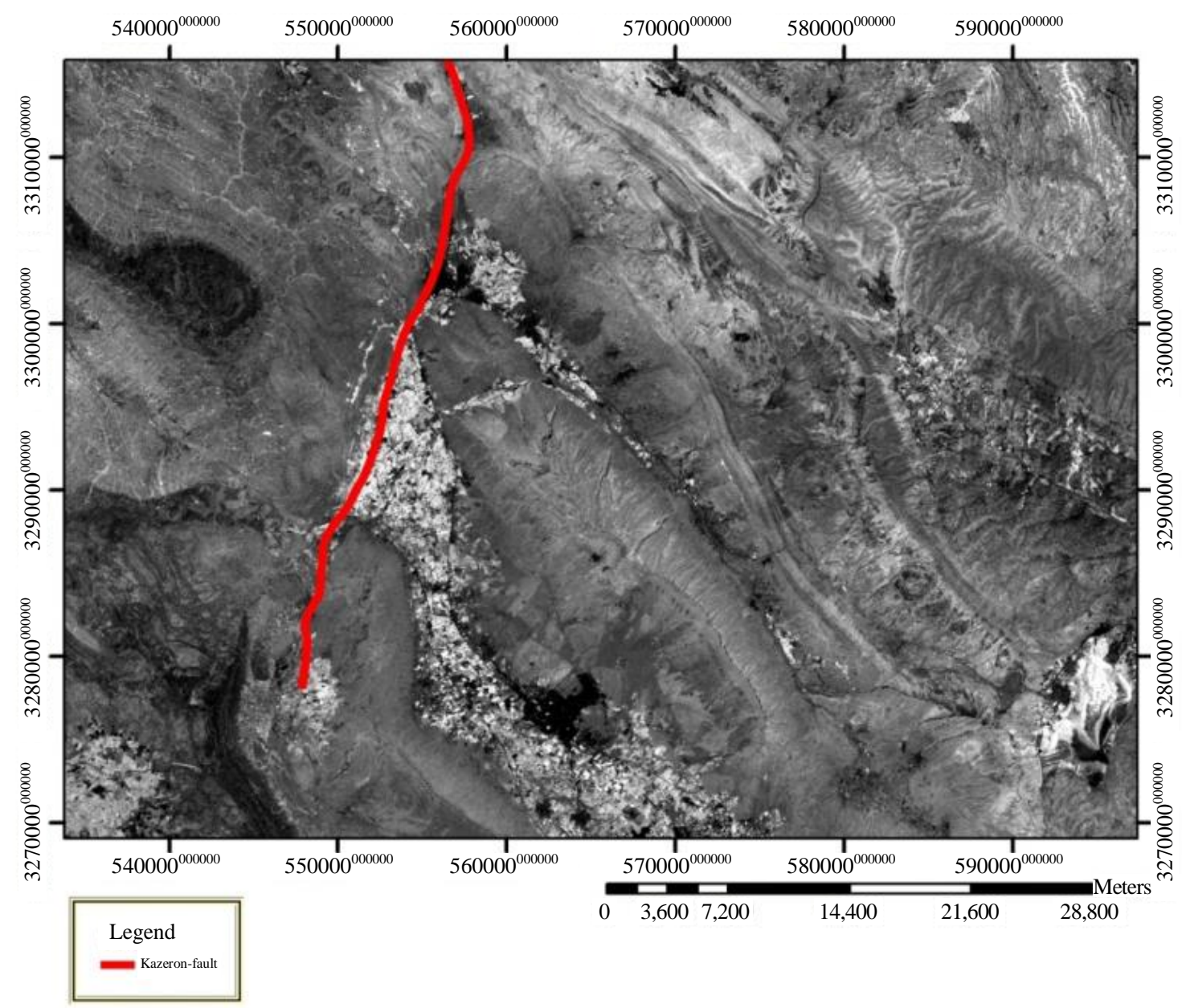

Figure 6. Image of normalized vegetation index, the vegetative areas are brighter than other areas in this image. 
such that the first axis is the maximum variance and the next, perpendicular to the first one, shows the remaining variance. Through this, from the $\mathrm{n}$ bands taking part in the transformation, n new PC bands which are not highly correlated are produced. Using the corresponding analysis matrices, it is revealed that PC1 has the largest amount of information, other PCs following it correspondingly. The proper PC for a particular phenomenon can be specified with regard to the spectral behavior of the phenomenon, the maximum reflection and absorption of the phenomenon among different bands, and information from correlation matrix.

PCA is one of the distinguished methods in analysis of telemetry images. Different objectives are pursued here, among which are: reduction of data dimensions, discovering the changes in images with different temporal conditions, and clarification of particular phenomena. In this method, data or image bands are put in a new space, and new components replace the former components and bands. In the new space, each new component is a linear combination of the former bands according to the following relation. Correlations are eliminated, and independent bands are produced (Figure 7):

$$
P c_{k}=\sum_{i=2}^{n} w i_{k} D N i,
$$

where $P c_{k}$ is the $k^{\text {th }}$ component, wi is the special vector, and $D N i$ is the light of the $i^{\text {th }}$ band.

\subsection{Band Ratio}

Band ratio is one of the commonly-used methods in image processing. It increases or decreases some particular noises and, by removing topographic effects and shadows, clarifies the borders (Figure 8). That is why band ratio is used in rock unit separation as well as in rock specification [16]. Plants, for example, in Landsat band 5 have the maximum reflection while in band 4 , they show the maximum absorption. With regard to this and by dividing band 5 onto band 4, one can clarify the plants. Some common ratios are as follows (Table 1 and Figure 8):

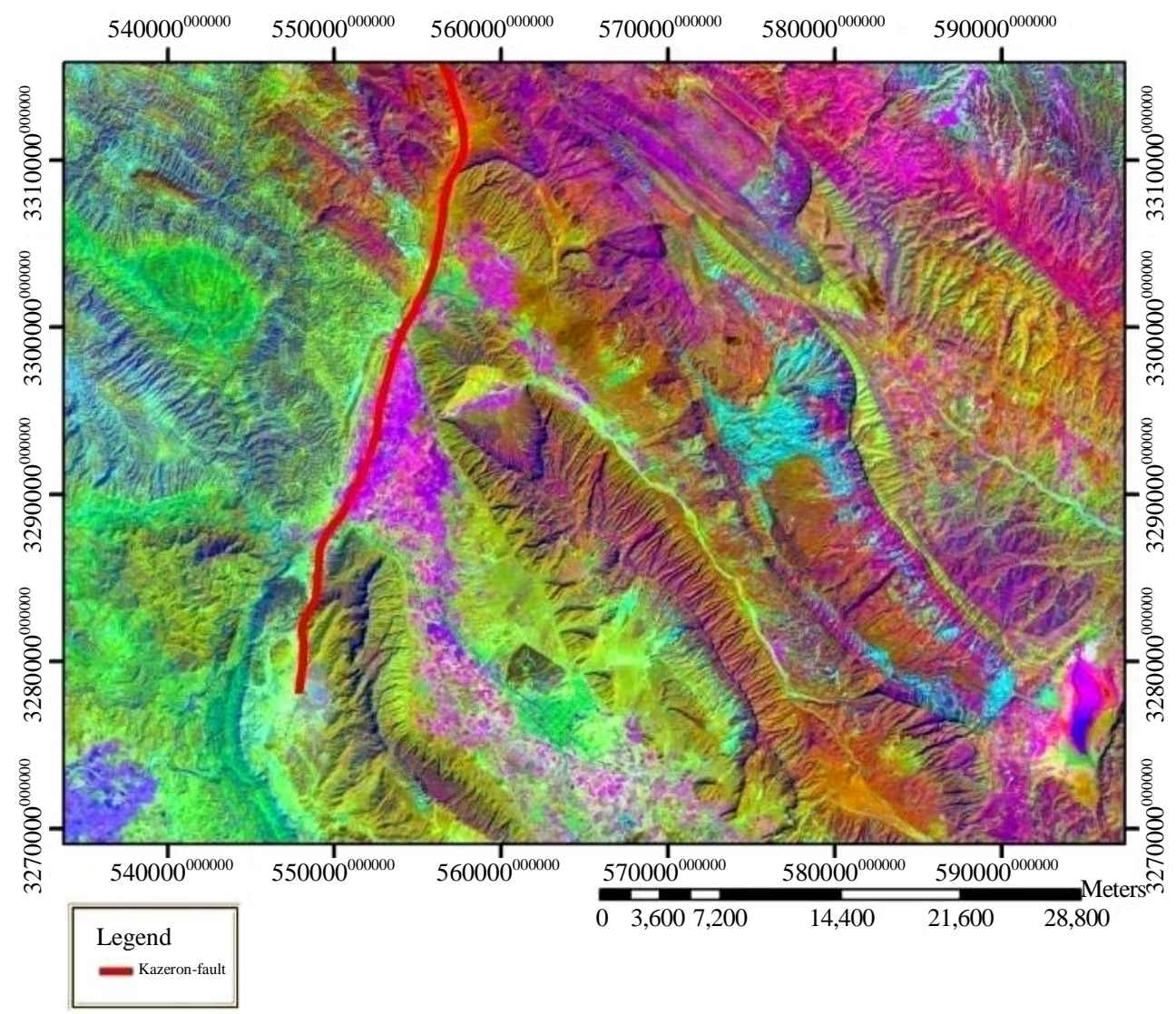

Figure 7. Images for RGB = PC1 - PC2 - PC3; Landsat image after administration of PCA. 


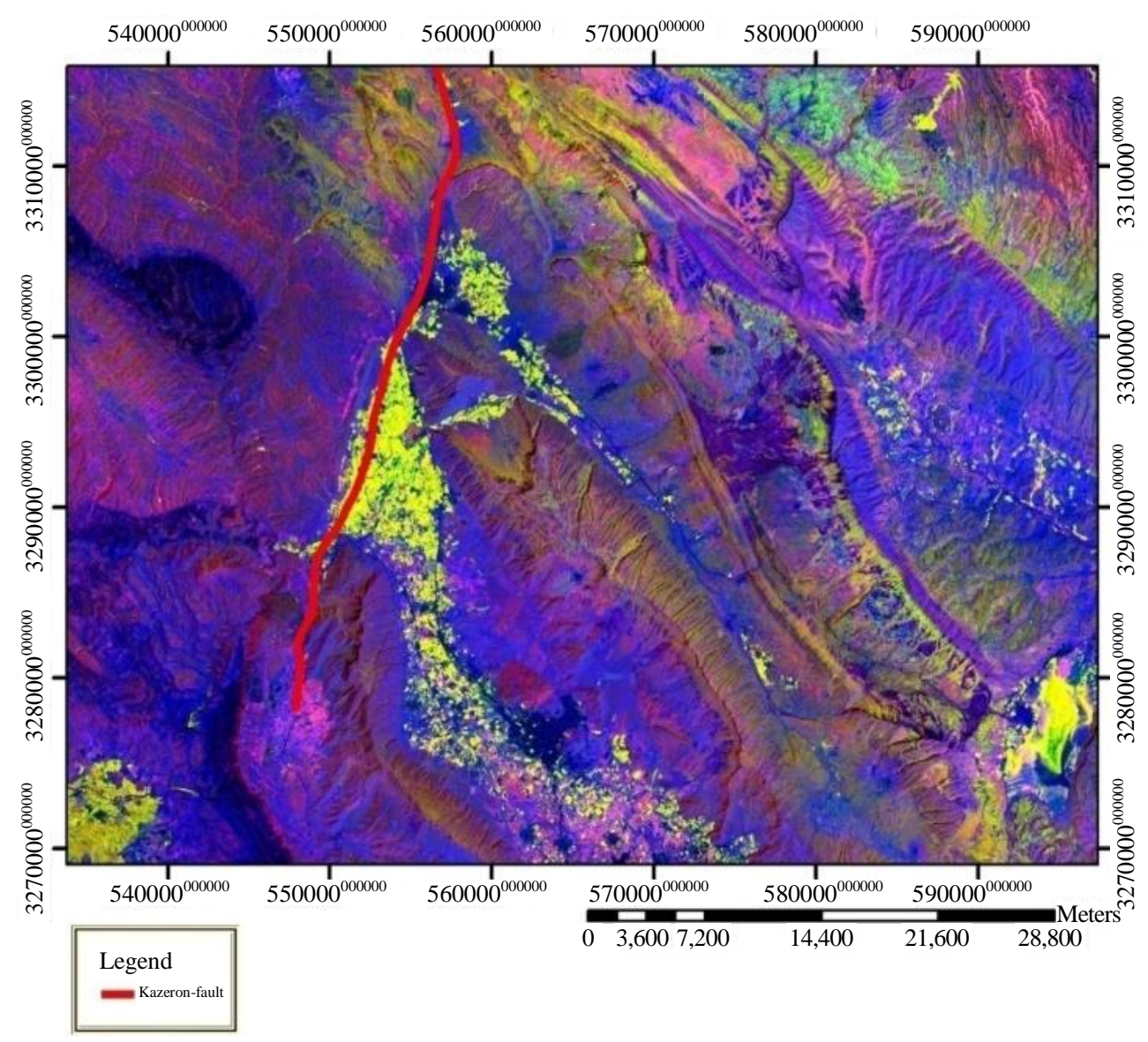

Figure 8. Image for band ratios with RGB =6/7, 5/4, 4/2.

Table 1. Band ratio method and its applications. Here 4/2, 5/4, and 6/7 ratios are respectively attributed to red, green, and blue bands.

\begin{tabular}{lc}
\multicolumn{1}{c}{ Application } & Band Ratio \\
\hline Separation of plants from non-plants & B5/B4 \\
Specification of hydrothermally altered rocks & B6/B7 \\
Separation of iron oxide & B4/B1 \\
\hline
\end{tabular}

\subsection{Filtering and Use of DEM Images}

Filtering is a type of changing spectral values; each pixel value would be, therefore, different from that of the neighboring one, thus creating different contrast when compared with the main image. A filtered matrix has odd number of cells (regarding the fact that a pixel must be at the center). With respect to the particular application, numerical value of the central cell is changed considering its neighboring cells. Administering sun-shading technique on DEM images is, also, a method in topography specification of an area. Using this technique, sunlight can be radiated onto the images in the desired direction, and the resulting shadows are later investigated. Filtering can be in $3 * 3,5 * 5$, or $7 * 7$ dimensions. The more the filter dimensions, the more the speed and the less the accuracy of filtering. Filtering is an important tool in gaining better vision of an area and detection of effects (Figures 9-11).

Different filters used in this section and explained in the following are as follows: high-pass filters, edge detector filters, and sun-angle filters. High-pass filters are detectors of edges. They only allow passage of gray pixels with high frequency. These filters just detect the edges and do not fade out other effects [17]. Edge detector 


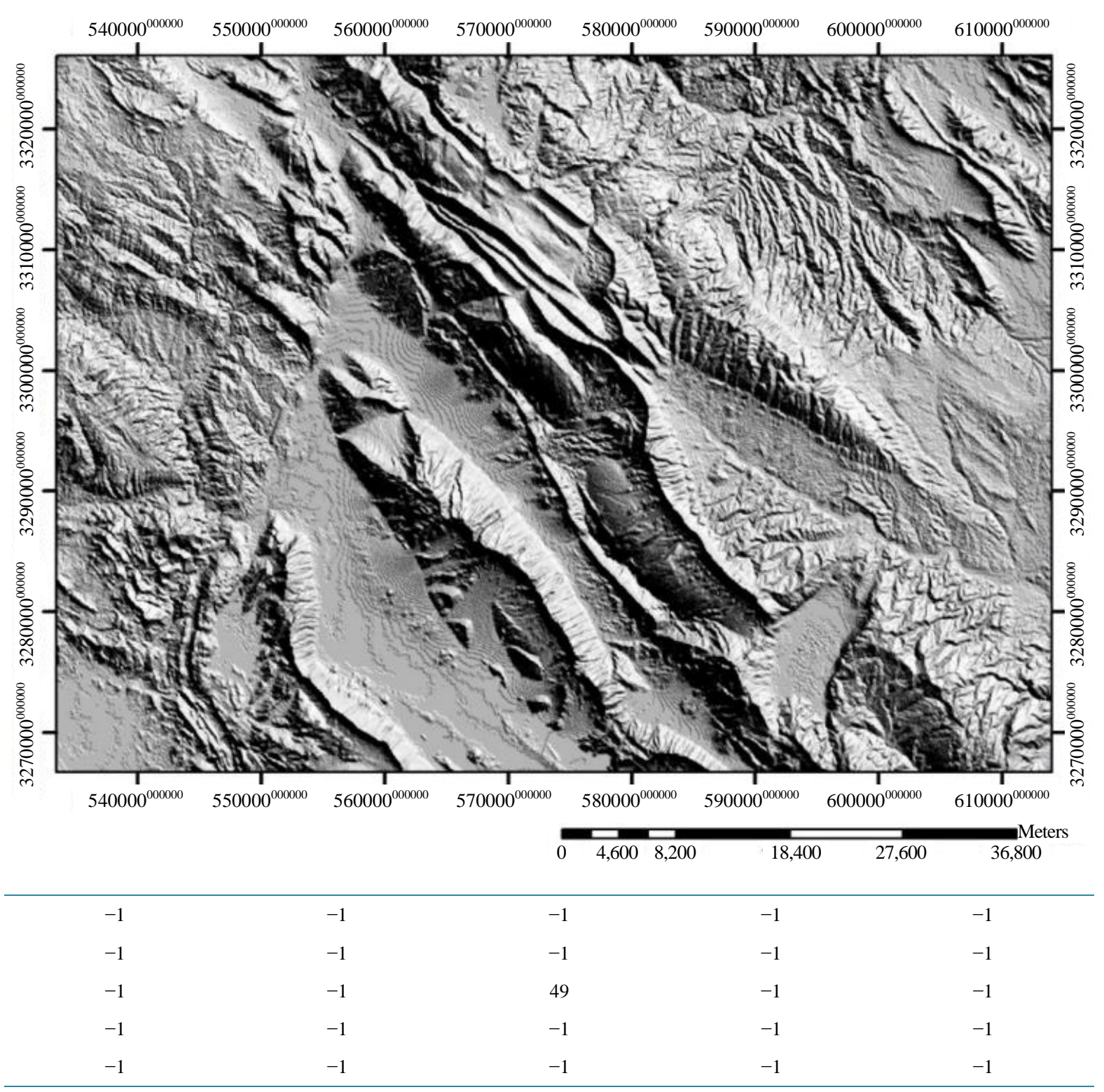

Figure 9. Filter image and filter matrix for high-pass filter (sharpen $5 * 5$ Ker.), the matrix contained in the filter is a $5 * 5$ matrix which shows the processes applied to the image.

filters, as their name suggests, detect edges such as structural lineaments, roads, and rivers, and are of significance in structural geology in detection of fault lineaments [18]. Sun-angle filters, finally, are among simple yet effective techniques in detection of sharp edges and borders such as fault lines and joints [19].

\subsection{Three-Dimensional Image of the Area}

Digital elevation model (DEM) can help us produce a three-dimensional view of the area. Here, the most practical data are STRM-sensor images, the same images which are used in the present paper (Figures 12-14). Also, through ER Mapper, three-dimensional image of the area was produced for different RGBs. Images reveal that the northern part of the study site has more topography than the southern one.

\section{Conclusions}

Using the mentioned images including the image with RGB $=457$, the gray-scale one, the filtered images, 


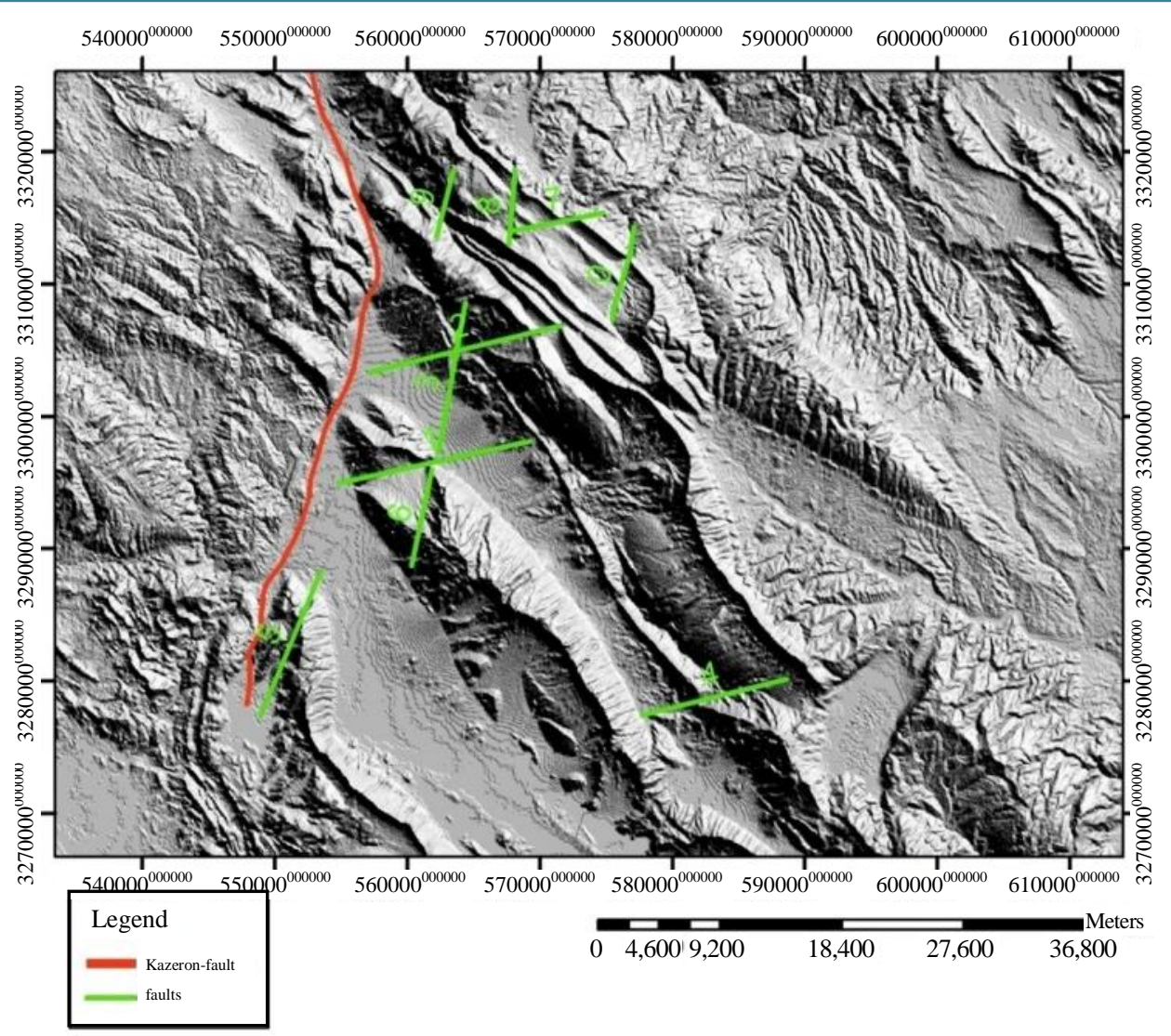

Figure 10. DEM image and the major and minor faults as obtained on a DE image.
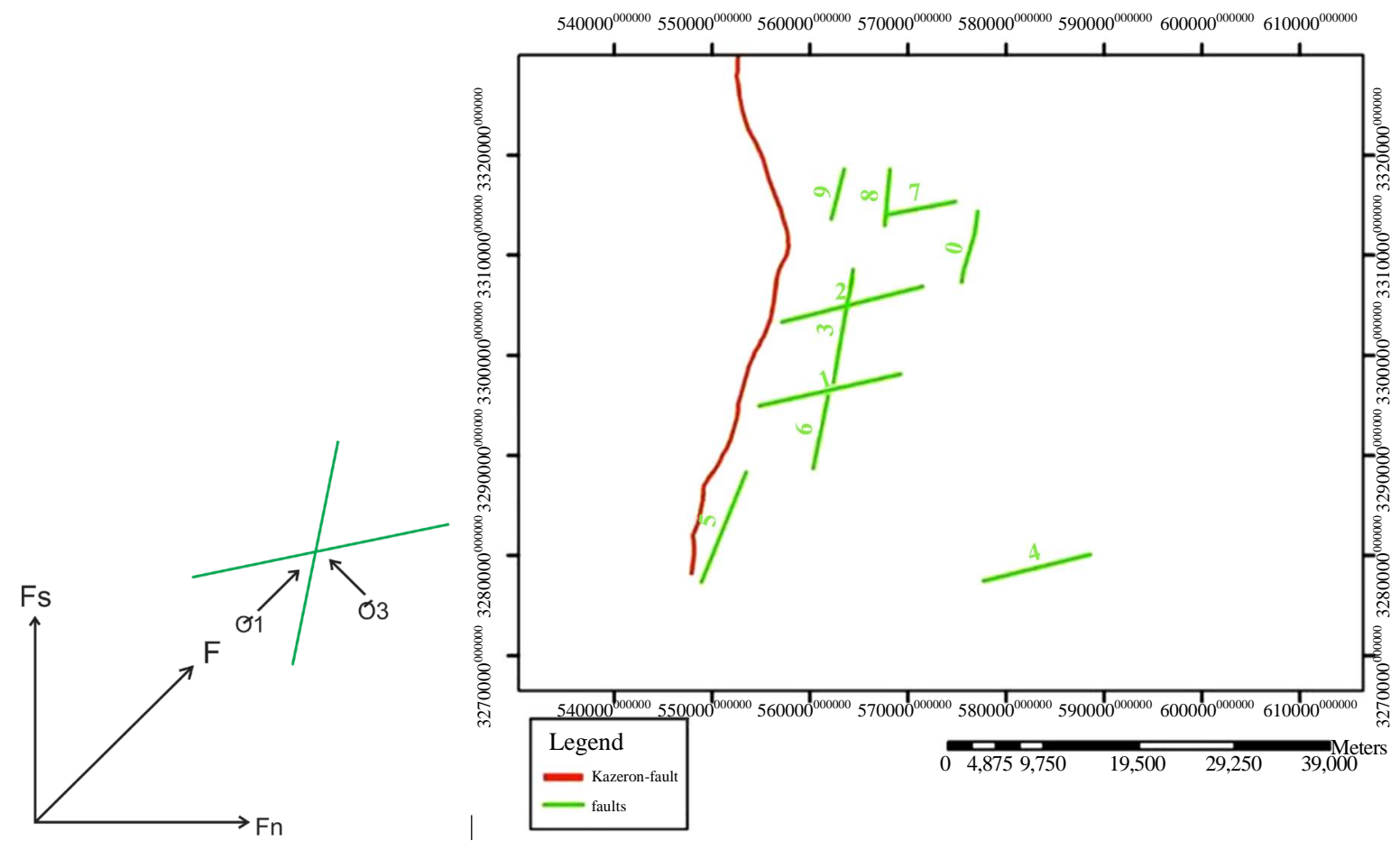

Figure 11. Status of forces on the fault $(a, b)$. 


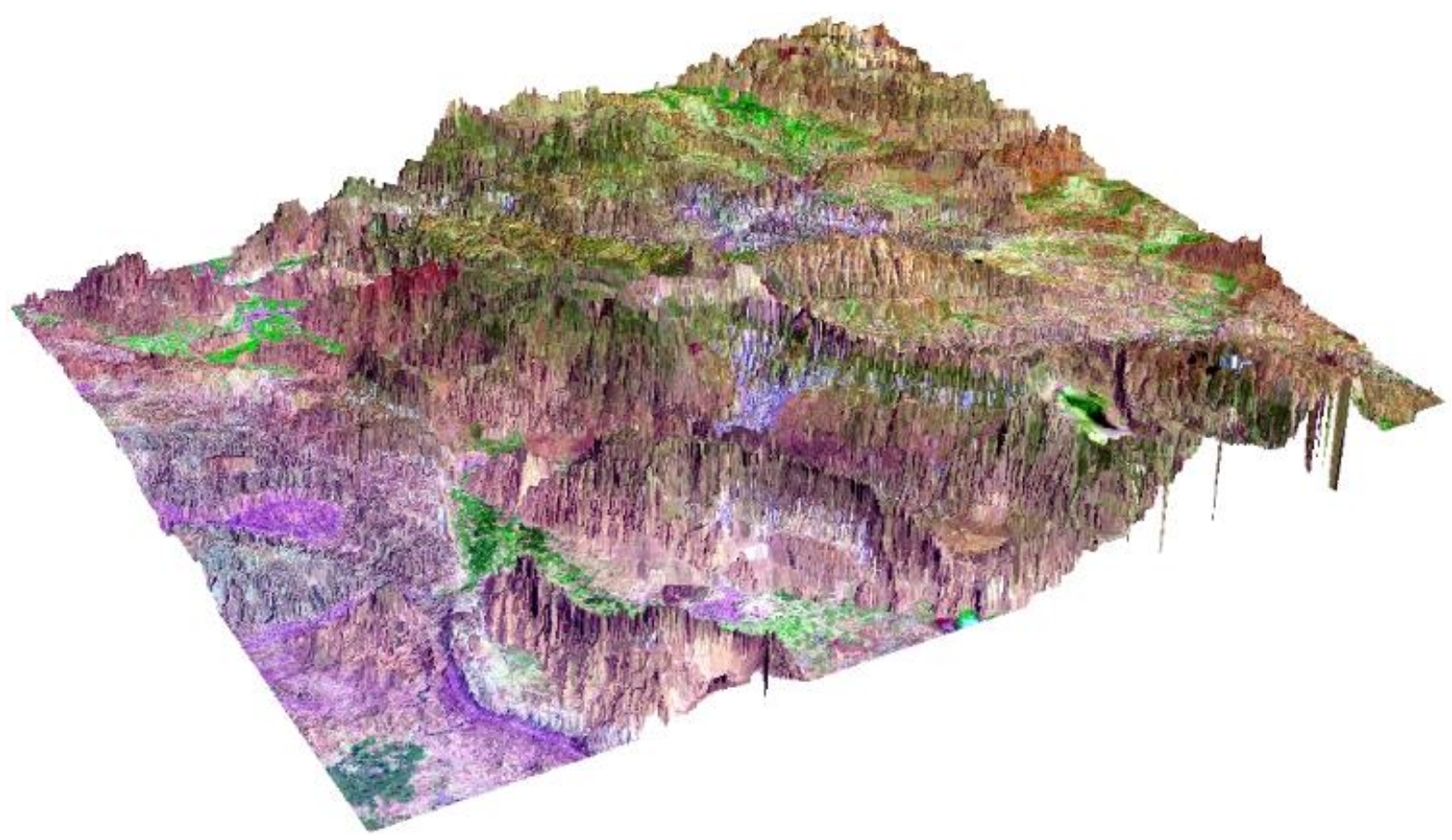

Figure 12. Three-dimensional image of RGB752 (from a north-eastern viewpoint).

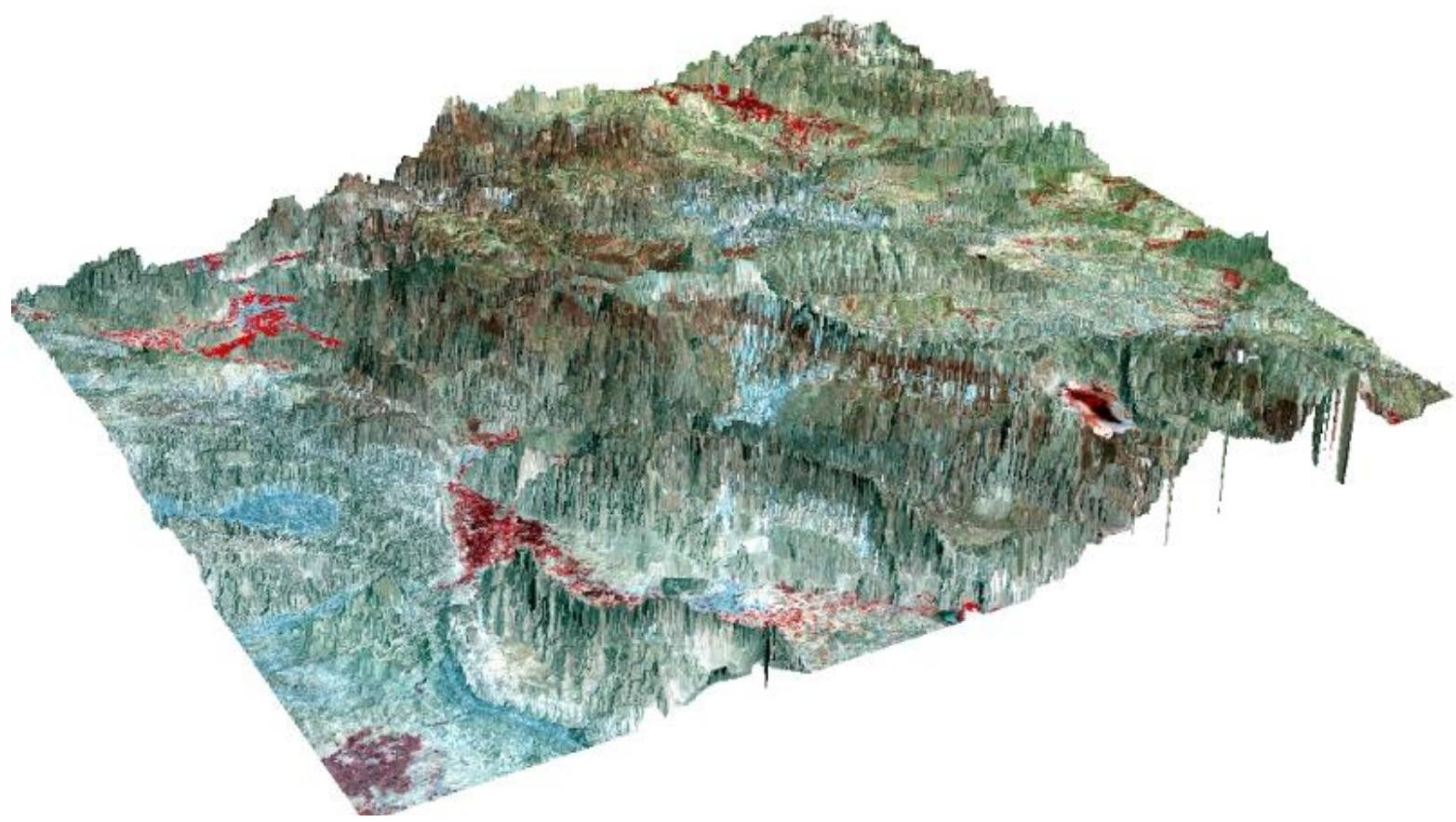

Figure 13. Three-dimensional image of RGB742 (from a north-eastern viewpoint).

uni-band image of PC1, DEM images with oriented shadows and images with specified band ratios, tectonic lineaments of the area were drawn. In order to produce the structural fractures map, the final map was drawn on the image with RGB = 457 as the optimal combination (Figure 15, Figure 16).

Due to the above discussions and results:

1) In telemetry studies using ER-Mapper, Sharpen $5 * 5$ Ker. and DEM are the best filters in representation of the fault; 


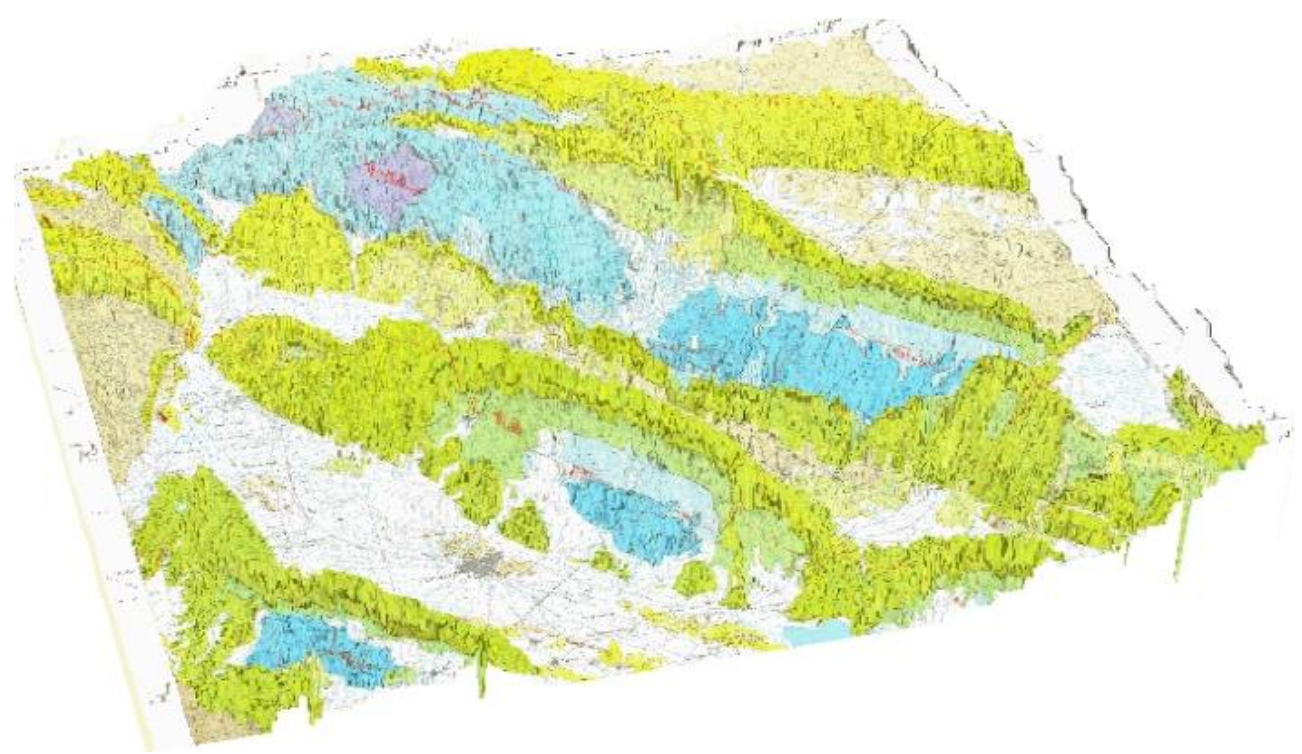

Figure 14. Three-dimensional geological 1:10,0000 map of Kazerun.

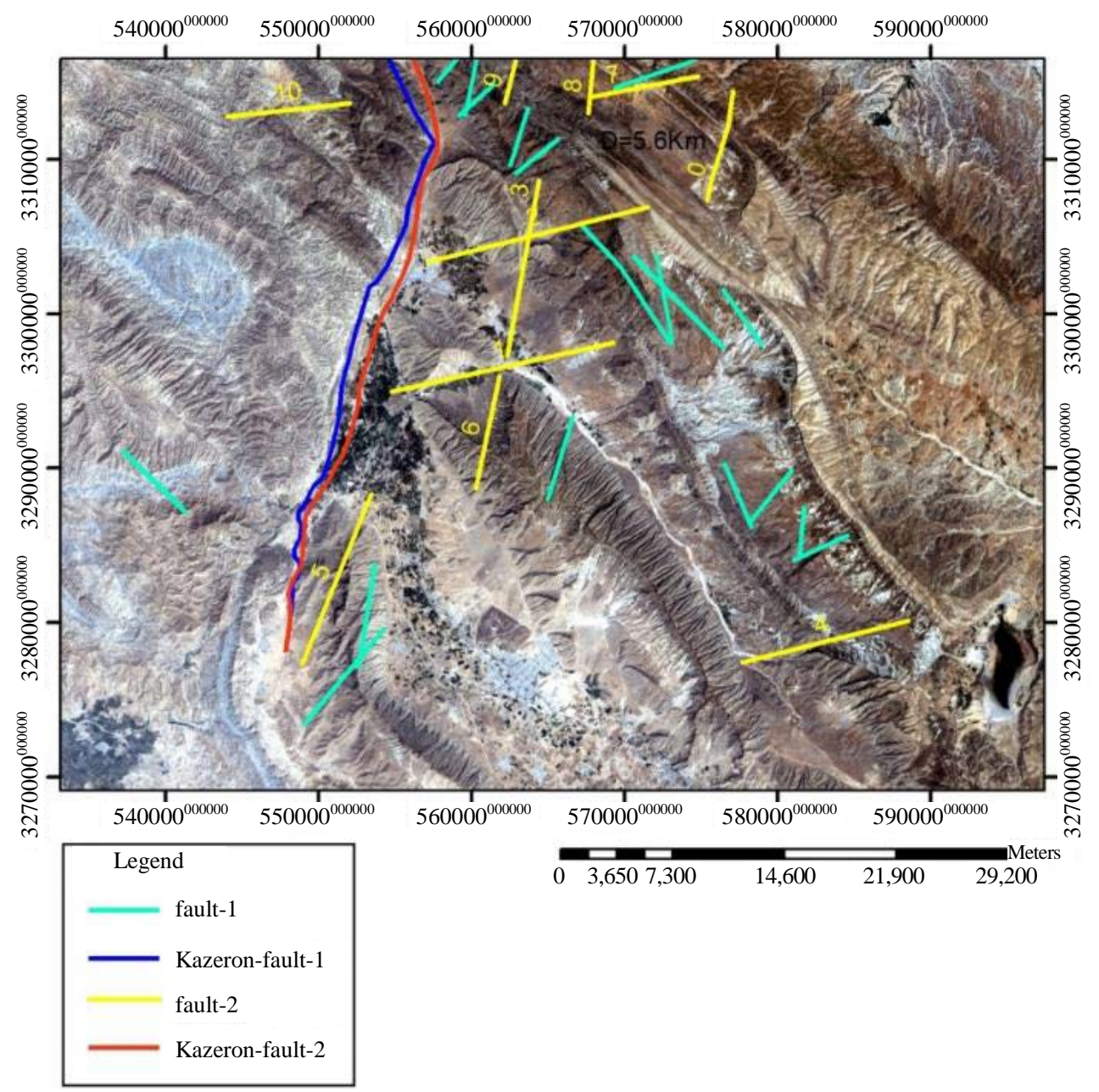

Figure 15. Major and minor structural fractures map (provided by Iranian National Oil Company based on satellite and Landsat images, Kazerun fault 1 and 2) with RGB $=457$. 


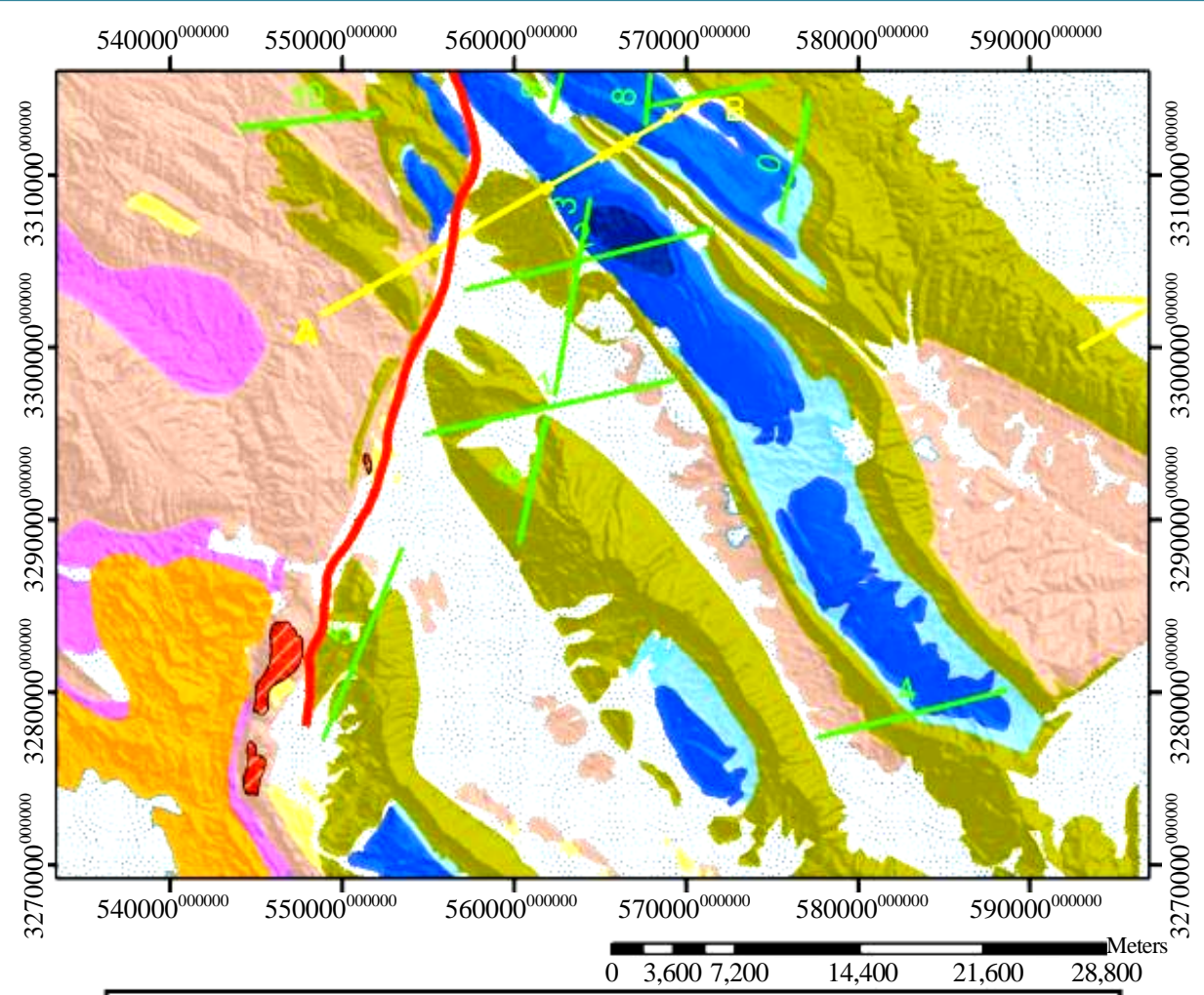

\begin{tabular}{|c|c|c|}
\hline \multicolumn{3}{|l|}{ Legend } \\
\hline — Kazeron-fault & Gachsaran-formation & Kagdumi-formation \\
\hline $\begin{array}{l}\text { Faults } \\
\text { A-B section }\end{array}$ & Asmari.jahrum-formation & Guri-mb \\
\hline sub recent lake beds & Pabdeh-formation & VZHurmuz-formation \\
\hline Bakhtiari-formation & Gurpi-formation & V/Fars-sea \\
\hline Agha jari-formation & sarvak-formation & \\
\hline Mishan-formation & llam.sarvak-formation & \\
\hline
\end{tabular}
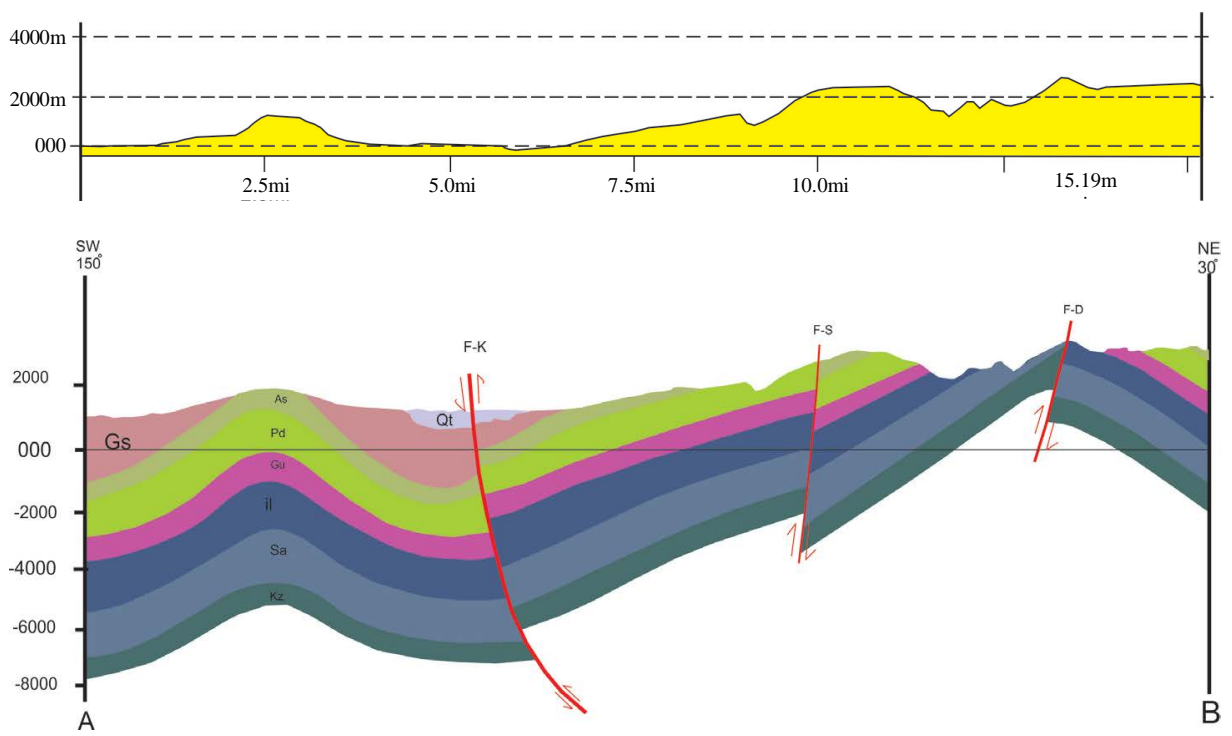

Figure 16. Detected faults at the study site on cross section AB. 
2) The extracted fault, as studied through telemetry methods, has a procedure alike to that of Kazerun faults with an almost parallel north-south direction;

3) Major and minor structural fractures map (provided by Iranian National Oil Company based on satellite and Landsat images, Kazerun fault 1 and 2) is shown for RGB $=457$ (Figure 16).

\section{References}

[1] Blaschke, T. (2010) Object Based Image Analysis for Remote Sensing. ISPRS Journal of Photogrammetry and Remote Sensing, 65, 2-16. http://dx.doi.org/10.1016/j.isprsjprs.2009.06.004

[2] Richards, J.A. and Richards, J. (1999) Remote Sensing Digital Image Analysis. Vol. 3, Springer. Heidelberg. http://dx.doi.org/10.1007/978-3-662-03978-6

[3] Campbell, J.B. (2002) Introduction to Remote Sensing. CRC Press. Boca Raton.

[4] Rogan, J. and Chen, D. (2004) Remote Sensing Technology for Mapping and Monitoring Land-Cover and Land-Use Change. Progress in planning, 61, 301-325. http://dx.doi.org/10.1016/S0305-9006(03)00066-7

[5] Dana, S., Almasian, M., Asadi, A., Pourkermani, M. and Goreshi, M. (2015) Measuring the Qatar-Kazeron Fault Dip Using Random Finite Fault Simulation of September 27, 2010 Kazeron Earthquake and Analytical Signal Map of Satellite Magnetic Data. Open Journal of Geology, 5, 73-82. http://dx.doi.org/10.4236/ojg.2015.52007

[6] Arian, M. and Nouri, R. (2015) Lineament Tectonics and Mineralizatin in Tarom Area, North Iran. Open Journal of Geology, 5, 115-125. http://dx.doi.org/10.4236/ojg.2015.53011

[7] Hajibapir, G., Lotfi, M., Zarifi, A.Z. and Nezafati, N. (2014) Application of Different Image Processing Techniques on Aster and ETM+ Images for Exploration of Hydrothermal Alteration Associated with Copper Mineralizations Mapping Kehdolan Area (Eastern Azarbaijan Province-Iran). Open Journal of Geology, 4, 582-597. http://dx.doi.org/10.4236/ojg.2014.411043

[8] Gupta, R.P. (2003) Remote Sensing Geology. Springer Science \& Business Media, Heidelberg. http://dx.doi.org/10.1007/978-3-662-05283-9

[9] Drury, S.A. and Drury, S. (2001) Image Interpretation in Geology. Blackwell Science, London.

[10] Rees, W.G. (2013) Physical Principles of Remote Sensing. Cambridge University Press, Cambridge.

[11] Ricchetti, E. (2000) Multispectral Satellite Image and Ancillary Data Integration for Geological Classification. Photogrammetric Engineering and Remote Sensing, 66, 429-435.

[12] Pohl, C. and Van Genderen, J.L. (1998) Review Article Multisensor Image Fusion in Remote Sensing: Concepts, Methods and Applications. International Journal of Remote Sensing, 19, 823-854. http://dx.doi.org/10.1080/014311698215748

[13] Alavi Panah, S. (2003) Application of Remote Sensing in Geology (Earth Sciences). Vol. 1, University of Tehran, Tehran.

[14] Chavez, P., Berlin, G. and Sowers, L. (1982) Statistical Method for Selecting Landsat MSS Ratios. Journal of Applied Photographic Engineering, 8, 23-30.

[15] Yang, J., Weisberg, P.J. and Bristow, N.A. (2012) Landsat Remote Sensing Approaches for Monitoring Long-Term Tree Cover Dynamics in Semi-Arid Woodlands: Comparison of Vegetation Indices and Spectral Mixture Analysis. Remote Sensing of Environment, 119, 62-71. http://dx.doi.org/10.1016/j.rse.2011.12.004

[16] Konecny, G. (2014) Geoinformation: Remote Sensing, Photogrammetry and Geographic Information Systems. CRC Press, Boca Raton.

[17] Schowengerdt, R.A. (2006) Remote Sensing: Models and Methods for Image Processing. Academic Press, Waltham.

[18] Babaahmadi, A., Mohajjel, M., Eftekhari, A. and Davoudian, A.R. (2012) An Investigation into the Fault Patterns in the Chadegan Region, West Iran: Evidence for Dextral Brittle Transpressional Tectonics in the Sanandaj-Sirjan Zone. Journal of Asian Earth Sciences, 43, 77-88. http://dx.doi.org/10.1016/j.jseaes.2011.08.012

[19] Babaahmadi, A. and Rosenbaum, G. (2013) Kinematics of the Demon Fault: Implications for Mesozoic Strike-Slip Faulting in Eastern Australia. Australian Journal of Earth Sciences, 60, 255-269.

http://dx.doi.org/10.1080/08120099.2013.762943 